\title{
Chinese Instructor's Vocational Ability: Basic Concept, Structure and Questionnaire Design
}

\author{
Xianhua Yang
}

College of Humanities \& Social Sciences of Shangluo University, Shangluo, Shaanxi, China

emery10818@sina.com

\begin{abstract}
Keywords: Instructor' vocational ability, Concept, Characteristic, Structure, Questionnaire.
Abstract. Study on chinese counselor's vocational ability has become a focus of current research in the field of higher education. Studies in this field are conducive to enriching the theories of counselors' profession or vocation, promoting college students' growth and development, and also developing the counselors's level. Counselor's vocational ability is a comprehensive ability in the process of their vacation, and is a collection of multi-levels and multi-types, which has basic, stable, and special characteristics. Counselor's vocational abilities mainly compose of two levels and ten categories, including the basic abilities (education, management, service, learning, innovation ability) and special abilities (cognition, emotion, will, behavior, personality ability). Finally, some requirements about questionnaire design are supplied.
\end{abstract}

\section{辅导员职业能力: 基本概念、结构与问卷设计}

\author{
杨宪华 \\ 商洛学院人文社会科学学院, 商洛, 陕西, 中国 \\ emery10818@sina.com
}

关键词:辅导员职业能力; 概念; 特征; 结构; 问卷

中文摘要.辅导员职业能力是当前我国高等教育领域研究的一个热点问题。该领域研究有利于 丰富辅导员专业化、职业化理论，有利于促进大学生的成长成才，有利于提升辅导员自身水 平。辅导员职业能力是一种在职业过程中表现出来的综合能力, 是一个多层次多类型的集合 体, 具有基本性、稳定性和特殊性特征。辅导员职业能力主要由基本能力（包括教育、管理、 服务、学习、创新五种能力）和特殊能力（包括认知、情感、意志、行为、个性）两层次十 大类组成。最后，提出了辅导员职业能力问卷设计的基本要求。

\section{1. 引言}

党的十六大以来，特别是《中共中央国务院关于进一步加强和改进大学生思想政治教育 的意见》（中发（2004）16 号）下发以来，高校深刻认识加强辅导员队伍建设的重要性和紧 迫性, 使辅导员专业化、职业化建设不断加强。党的十八大报告指出, 要把立德树人作为教 育的根本任务，培养德智体美全面发展的社会主义建设者和接班人，培养学生社会责任感、

创新精神、实践能力, 这对在高校育人过程中发挥重要作用的高校辅导员队伍及辅导员职业 能力提出了更高的要求。2014年3月, 教育部出台了《高等学校辅导员职业能力标准 (暂行)》, 建立了辅导员职业相对独立的知识和理论体系，为辅导员开展思想政治教育、党团和班级建 设、学业指导、日常事务管理、心理健康教育与咨询、网络思想政治教育、危机事件应对、 理论与实践研究等实际工作提供了制度依据。目前, 高校辅导员职业能力研究已经成为当前 我国高等教育领域研究的一个热点话题, 学者们的研究不仅在理论上而且在实践上都取得了 
一定的成果。然而, 不难发现, 辅导员职业能力的研究在我国还处于起步阶段, 目前还存在 概念不够清晰、结构众说纷纭、辅导员自身发展路径狭窄等问题。这不仅直接影响大学生的 培养质量, 也阻碍了辅导员职业化发展的步伐。在这一新的历史背景下, 如何有效测量辅导 员职业能力成为了迫切需要解决的关键问题，而这正是本课题拟解决的主要问题。

本研究在回顾已有研究成果基础上, 提出辅导员职业能力的结构, 并规划其问卷的编制, 为提升高校辅导员职业能力提供借鉴参考。本研究通过探索辅导员职业能力的结构，为高校 辅导员队伍建设提供了一个新的视角, 有利于丰富辅导员专业化、职业化理论, 可以为高校 推进辅导员队伍建设提供参考依据, 可以作为高校辅导员队伍准入、考核、培养、发展、退 出机制的测评工具; 有助于其更加有效的开展大学生教育管理服务工作, 将大学生培养成为 可靠的社会主义事业的建设者和接班人，促进大学生的成长成才; 辅导员职业能力研究是辅 导员个人职业生涯规划的必由之路, 肩负起大学生的 “政治上的引领者, 学习上的教授者, 生活上的指导者, 人生中的引导者” 的重托和职责, 能够提升辅导员职业自信心和职业归属 感，增强广大师生和全社会对辅导员工作的职业认同，为辅导员自身主动提升专业素养和职 业能力提供了路径和方向。该研究对提升辅导员职业能力具有一定的现实意义。

\section{2. 辅导员职业能力的概念及特征}

\section{1 基本内涵}

《高等学校辅导员职业能力标准 (暂行)》将辅导员职业概括为 “辅导员是高等学校教 师队伍和管理队伍的重要组成部分, 具有教师和干部的双重身份。辅导员是开展大学生思想 政治教育的骨干力量, 是高校学生日常思想政治教育和管理工作的组织者、实施者和指导者。 辅导员应当努力成为学生的人生导师和健康成长的知心朋友。” 但目前关于辅导员职业能力 还没有形成一个公认的概念, 学者们对于辅导员职业能力内涵的理解还没有达成共识。赖彩 虹（2010）认为[1], 辅导员职业能力是一种在职业过程中表现出来的综合品质, 是多种能力 的系统集合, 包括一般能力、专业能力和关键能力。韩冬等 (2011) 则将辅导员职业能力定 义为: 从事高校辅导员工作所必备的, 以其拥有的知识和技能为基础, 根据自身的特点和优 势, 在不断学习中创新, 在不断创新中整合各方面资源, 培育和积淀出符合自身特色的综合 能力[2]。此外, 与辅导员职业能力相关的一个概念是职业素养, 它是辅导员作为学生工作者 必须遵守的行为规范, 是辅导员各方面素质的综合体现。一些学者认为辅导员职业素养包含 职业道德、职业意识、职业理想、职业知识、职业技能、职业行为等一系列要素, 这体现了 “大素养小能力” 的观点。而另一些学者则将职业能力的内涵扩展到更为广阔的范围, 运用 素质能力法将职业知识、职业素养和职业技能纳入职业能力体系当中。不论这两种观点孰是 孰非, 都体现出职业素养与职业能力之间的重要联系, 两者密不可分。通过梳理辅导员职业 素养各组成部分的涵义与关系, 有利于我们更加全面的理解辅导员职业能力的内涵。我们认 为, 高校辅导员职业能力是一种在职业过程中表现出来的综合能力, 是一个多层次多类型的 集合体，既包括基本能力也包括特殊能力。

\section{2 主要特征}

《高等学校辅导员职业能力标准 (暂行) 》将职业能力特征概括为 “政治强、业务精、 纪律严、作风正。具备思想政治教育工作相关学科的宽口径知识储备。具备较强的组织管理 能力和语言、文字表达能力, 及教育引导能力、调查研究能力等”。我们认为辅导员职业能 力的主要特征是：一是基本性。这是辅导员职业能力最一般、最基本的特征, 是每一名辅导 员都必须具有的最基本的职业能力。辅导员之间在职业能力上的差异，不是 “有”或 “无” 的差异，而是水平 “高” 或 “低” 的差异，“完整” 或 “不完整” 的差异，以及功能发挥程 度上的差异。二是稳定性。辅导员职业能力是辅导员个体先天生遗传和后天社会环境交互作 用的结晶和沉淀, 是经过 “内化一外化一内化” 反复多次相互转化而形成的内在的、相对稳 
定的职业特性及其结构。辅导员职业能力一旦形成就具有一定的稳定性, 既不会因一时一事 的变化而改变或消失, 也不会因一时一事的出现而发展。三是特殊性。辅导员职业能力是辅 导员特殊职业的表现, 在心理层面上具有特殊性, 反映了辅导员在认知、情感、意志、行为 及其个性等心理方面与其他职业的差别。

\section{3. 辅导员职业能力的结构}

\section{1 以往研究}

辅导员的职业能力高低是学生工作顺利开展和大学生成长成才的重要影响因素，构建合 理的职业能力结构有益于科学衡量辅导员的职业水平, 对提升辅导员职业能力具有重要意义。 学者们基于对辅导员职业能力内涵理解的不同, 构建出各具特点的辅导员职业能力结构。有 的从国家政策层面理清辅导员职业能力的分析思路, 有的在借鉴德国学者对职业能力划分的 基础上构建辅导员职业能力结构, 还有的吸收管理学学科理论开辟新的研究视角。陈岩松运 用人力资源理论和知识, 通过对多所高校辅导员进行行为事件访谈, 构建出包含职业态度、 知识一技能和个性鬼力等三个维度, 服务意识、分析能力、自信心等十三项胜任要素的高校 辅导员胜任力模型[3]。李双贵等基于斯腾伯格的三元智力理论提出了辅导员所应具备的能 力: 学习能力、应对能力、教育能力、就业指导、心理辅导、解决问题的能力、创新能力和 科研能力[4]。罗勇等 (2016) 在剖析当前辅导员职业能力发展存在的主要问题基础上, 探讨 了辅导员职业能力量化评价指标体系的构建[5]。刘金华 (2010) 把辅导员的能力分为了三类: 基础能力 (包括管理能力、学习能力、研究创新能力等) 、关键能力 (主要是指学生事务管 理的能力）、核心能力（主要是指思想政治教育能力）[6]。邵国平等（2013）编制了由教育、 管理、服务和专业态度构成的高校辅导员职业能力问卷, 并验证了其较好的信效度及适用性 [7]。这些成果都为今后研究辅导员职业能力的测量问题提供了借鉴和启示。

\section{2 结构的新构想}

在理论思考和实证研究基础上, 结合访谈、调研、讨论和座谈结果, 我们形成的辅导员 职业能力结构是一个由两层次十大类能力组成的系统。辅导员职业能力分为基本能力和特殊 能力两个层次。其中, 基本能力包括教育能力等五种类型: 教育能力是指高校辅导员有目的、 有计划、有组织地对大学生产生影响, 教育、引导提高他们的知识和技能的一种能力。如, 理想信念教育、爱校荣校教育、廉政教育、感恩教育、校纪校规教育、安全教育、文明行为 教育、诚信教育、职业道德教育、网络思想政治教育、组织校园文化活动等。管理能力是指 高校辅导员以学生为中心在学生事务管理与协调中展现的一种能力, 包括对日常事务管理、 引领学生成长、稳定工作、学生干部管理、困难资助、奖罚管理等日常事务管理、党团组织 管理、班级建设管理、危机事件应对、领导、组织协调等等。着眼于全面育人, 统筹学生的 学习与生活、思想素质与专业素质、优秀学生与问题学生等多项工作。服务能力是指辅导员 能及时了解学生的需求, 帮助学生解决实际困难并使学生从中受益的一种能力。比如对学生 进行人生规划、对学生进行心理辅导、服务学生成长成才学业指导与服务心理健康咨询与服 务职业规划与服务就业指导与服务创业指导与服务等等。学习能力是指高校辅导员学习相关 知识的方法与技巧。从类型上主要包括学习专注力、学习成就感、自信心、思维灵活度、独 立性和反思力。从内容层面可以分为政策学习、理论学习、专业学习、信息化学习等。其中, 信息化学习, 要树立信息化和大数据工作思维, 学习并运用信息化技术和平台, 加强网络思 想教育和网络文化学习。创新能力是指高校辅导员在工作与各种实践活动中不断提供具有价 值的思想、新理论、新方法的能力。例如, 辅导员事务工作创新、理论研究创新、实践探索 创新等。此外, 特殊能力主要包括认知能力、情感能力、行为能力、意志能力、个性修养。 


\section{4. 辅导员职业能力问卷设计}

\section{1 编制原则}

问卷编制遵循以下基本原则：依据理论构想拟编制两个分问卷，一般能力问卷包括教育 能力等 5 个维度, 特殊能力问卷包括认知能力等 5 个维度; 以已编制的题项为参照, 选取已经 通过大量研究证实确实对职业能力产生影响的题项为候选内容; 不求完全, 但要保证构想主 要能力和维度包含其中; 紧密结合我国辅导员职业能力实际, 力争自编而不是改编某些问卷; 两个分问卷及其各维度一律正向命名, 但适度采用反向记分方式以控制顺从性作答偏差。

\section{2 技术规定}

从技术层面有如下规定：问卷适用对象为陕西省高校一线专职辅导员；问卷为自陈问卷， 题项统一使用第一人称或无人称的短句; 计分方式统一采用1-5级计分方式，1=完全不符合， $5=$ 完全符合; 各分问卷、维度需满足的心理测量学指标：标准化因子负荷不低于 0.4 , 项目与 所在维度平均分的相关系数大于 0.4 , 信度系数在 0.7 以上, 提供包括内容效度、效标效度、结 构效度在内的多种效度指标; 采用差异性 $t$ 检验进行项目分析, 采用探索性因素分析初步形成 问卷结构, 通过验证性因素分析, 进一步确立问卷结构, 最后形成正式问卷的使用手册。

\section{3 题项来源}

题项的主要来源有：参考国内外同类量表中的有关项目；分析国内外有关辅导员职业能 力方面的研究，对存在的问题进行归类和分析，抽取出一些有代表性的问题编写相应项目; 采用半开放式问卷, 分别调查大学生、用人单位及辅导员自身对辅导员职业能力的需求, 形 成问卷题项; 通过访谈辅导员队伍管理的领导及部分优秀辅导员，形成辅导员职业能力题项。

\section{致谢}

本文系陕西省高校辅导员工作研究课题 (项目编号:2016FKT23) 和商洛学院学生工作研究 课题 (项目编号:XSGZ16001) 阶段性成果。

\section{References}

[1] Caihong Lai, On College Counselors' Occupat ional Competency, Journal of College Advisor , vol. 3, pp. 80-82, 2010.

[2] Dong Hani and Xinhua Bi, The formation and promotion of College Counselors' professional ability, Leading Journal of Ideological \& Theoretical Education , vol.11, pp. 122-124, 2011.

[3] Yansong Chen, Competency model ing of political instructors in the university: An empirical study, Journal of Higher Education, vol.4, pp. 84-89, 2010.

[4] Shuanggui Li, On the composition of College Counselors' Professional Competence, Chinese Vocational and Technical Education, vol. 27, pp. 31-34, 2009.

[5] Yong Luo, Jianbin Du and Xuehua Li, Construction of evaluation system of College Counselors' Professional Competence, Education Review, vol. 4, pp. 120-123, 2016.

[6] Jinhua Liu, Analysis on the structure of College Counselors' Professional Competence, College Advisor, vol. 3, pp. 18-20, 2010.

[7] Guoping Shao, Delu Miao and Yang Lin, The Structure and Measurement of Occupational Ability in College Counselors, Psychological Research, vol.2, pp. 85-89, 2013. 